\title{
及-Adrenergic Signaling Regulates Evolutionarily Derived Sleep Loss in the Mexican Cavefish
}

\author{
Erik R. Dubouéa Richard L. Borowsky ${ }^{a} \quad$ Alex C. Keene ${ }^{b}$ \\ a Department of Biology, New York University, New York, N.Y., and ${ }^{b}$ Department of Biology, University of Nevada, \\ Reno, Nev., USA
}

\section{Key Words}

Astyanax · Mexican cavefish · Sleep · Propranolol ·

Catecholamine

\begin{abstract}
Sleep is a fundamental behavior exhibited almost universally throughout the animal kingdom. The required amount and circadian timing of sleep differs greatly between species in accordance with habitats and evolutionary history. The Mexican blind cavefish, Astyanax mexicanus, is a model organism for the study of adaptive morphological and behavioral traits. In addition to loss of eyes and pigmentation, cave populations of $A$. mexicanus exhibit evolutionarily derived sleep loss and increased vibration attraction behavior, presumably to cope with a nutrient-poor environment. Understanding the neural mechanisms of evolutionarily derived sleep loss in this system may reveal critical insights into the regulation of sleep in vertebrates. Here we report that blockade of $\beta$-adrenergic receptors with propranolol rescues the decreased-sleep phenotype of cavefish. This effect was not seen with $\alpha$-adrenergic antagonists. Treatment with selective $\beta 1-, \beta 2-$, and $\beta 3$-antagonists revealed that the increased sleep observed with propranolol could partially be explained via the $\beta 1$-adrenergic system. Morphological analysis of catecholamine circuitry revealed conservation of gross catecholaminergic neuroanatomy between surface and
\end{abstract}

\section{KARGER \\ Fax +4161306 1234 \\ E-Mail karger@karger.ch}

www.karger.com
(C) 2012 S. Karger AG, Basel

0006-8977/12/0804-0233\$38.00/0

Accessible online at: www.karger.com/bbe cave morphs. Taken together, these findings suggest that evolutionarily derived changes in adrenergic signaling underlie the reduced sleep of cave populations.

Copyright $\odot 2012$ S. Karger AG, Basel

\section{Introduction}

Astyanax mexicanus (A. mexicanus) is a powerful model for studying the genetic basis of evolutionary phenomena including developmental, morphological, and behavioral trait variation. A. mexicanus consists of numerous populations of eyed 'surface' morphs that live in the rivers and streams of Northeast Mexico and Texas, and 29 geographically isolated blind and depigmented cave morph populations inhabiting the region of the Sierra de El Abra in Northeast Mexico [Mitchell et al., 1977]. The invasion of caves by ancestral surface populations occurred in 2 distinct waves over periods ranging from 2 to 3 million years ago [Dowling et al., 2002; Ornelas-Garcia et al., 2008; Strecker et al., 2003, 2004]. In addition to morphological traits, a number of behaviors

Co-corresponding author: Richard L. Borowsky Department of Biology

1009 Silver Center, 100 Washington Square East New York, NY 10003-6688 (USA)

Tel. +1 212998 8260, E-Mail Rb4@nyu.edu

Alex C. Keene

Department of Biology, University of Nevada

1664 N. Virginia Ave, Mailstop 314

Reno, NV 89557 (USA)

Tel. +1 775784 6083, E-Mail AKeene@ unr.edu 
have evolved in response to a dramatically altered cave habitat. In contrast to rivers where photosynthesis-driven plant growth and constant water flow provide an abundance of food, the cave environment is characterized by a lack of photosynthesis, reduced food availability, and nearly constant water temperatures [Poulson, 1969]. A. mexicanus cave morphs have developed a number of metabolic and behavioral traits, presumably to cope with this environment, including increased mechanosensory capabilities, a keen ability to find mates, and a hypoactive metabolism [Burt de Perera, 2004; Filippi et al., 2010; Plath et al., 2006; Protas et al., 2008].

We previously reported that $A$. mexicanus cavefish have evolved a dramatically reduced sleep phenotype, presumably to increase the time available for foraging in a food-poor cave environment [Duboue et al., 2011]. Modulators of neurotransmission have a conserved role in the regulation of sleep [Cirelli, 2009]. For example, the neuropeptide orexin promotes sleep in fish and mammals [Lin et al., 1999; Prober et al., 2006; Yokogawa et al., 2007]. Elevated serotonin signaling in mice selectively increases REM sleep, suggesting a sleep-promoting role for serotonin [Wisor et al., 2003]. Conversely, mice lacking norepinephrine and epinephrine have an increase in total sleep and a decrease in sleep latency, and mice lacking histamine show an increase in sleep, indicating these neurotransmitters are wake promoting systems [Hunsley et al., 2006; Parmentier et al., 2002]. The amino acid neurotransmitters GABA and glutamate have also been implicated in the regulation of sleep. Injection of glutamate, or inhibition of GABA signaling in the dorsal subcoeruleus, a brain region involved in REM sleep, potently induces REM sleep [Pollock and Mistlberger, 2003; Simon et al., 2011]. Furthermore, pharmacological blockade of the glutamate N-methyl-daspartic acid (NMDA) receptor disrupts sleep [Stone et al., 1992]. Therefore, diverse neurotransmitter systems regulate sleep, and pharmacological manipulation of these systems may provide critical insight into the molecular basis of sleep-wake regulation. Given the dramatic differences in sleep between the surface and cave morphs as well as the conserved role for neurotransmitter systems in sleep, we sought to examine the role of neurotransmitter systems in evolutionarily derived sleep loss.

In this study, we pharmacologically disrupted neurotransmitter signaling to gain insight into the molecular basis of evolutionarily derived sleep loss in A. mexicanus. We reasoned that a pharmacological manipulation of an evolved wake-promoting system in A. mexicanus cave morphs would be affected differentially between surface and cave morphs. Here we identify a role for the noradrenergic system in the altered sleep/wake regulation exhibited by cave morphs. These findings are consistent with a conserved wake-promoting role for norepinephrine in flies, fish, and humans [Cirelli et al., 2005; Lebestky et al., 2009; Rihel et al.; 2010a]. We find that propranolol, a general inhibitor of $\beta$-adrenergic signaling, significantly increases sleep in cavefish, but not surface fish. There were no significant effects with $\alpha$-adrenergic antagonists suggesting the role is specific to the $\beta$-adrenergic system. Neuroanatomical analysis revealed striking conservation of catecholamine neuron morphology between surface and cavefish. These findings support the notion that evolutionarily derived sleep loss in cavefish populations may be due to hyperactive noradrenergic signaling and that the wake-promoting role of $\beta$-adrenergic signaling in cave populations is likely due to alterations in neural activity rather than changes in brain morphology. Our study is the first systematic study examining the contribution of distinct neurotransmitter classes to sleep regulation in $A$. mexicanus.

\section{Materials and Methods}

\section{Animal Maintenance and Behavioral Analysis}

Fish were housed in the core-fish facility at NYU with water temperature maintained at $21 \pm 1{ }^{\circ} \mathrm{C}$ and set to $12: 12$ light/dark cycles. Husbandry was carried out as previously described [Borowsky, 2008]. A. mexicanus breeders were fed a high-fat diet consisting of liver paste and live black worms (Lumbriculus variegates) for 2 weeks prior to breeding. On the night before breeding, breeder fish were moved to individualized tanks and the temperature was raised to $25 \pm 1{ }^{\circ} \mathrm{C}$. A. mexicanus fry were fed a daily diet of Artemia salina (Jehmco Fish Supplies). Behavioral testing took place in 100-well plates, and sleep was assayed in 2122 days post-fertilization (dpf) A. mexicanus surface and Pachón cave morphs as previously described [Duboué et al., 2011]. The time of behavioral testing (21-22 dpf) is pre-sexual differentiation and therefore fry are intersex. All recordings were carried out in a recording chamber with the temperature maintained at $21 \pm$ $1^{\circ} \mathrm{C}$. The recording chamber was illuminated constantly with a custom designed IR LED source $(940 \mathrm{~nm})$ as well as a 175-lux LED white light, which illuminated for 12 h (10:00 a.m. to 10:00 p.m.). Following $18 \mathrm{~h}$ of acclimatization, either control dimethyl sulfoxide solvent (DMSO) or freshly prepared (prepared the morning of administration) drug dissolved in DMSO was added to each well and behavior was recorded for $24 \mathrm{~h}$. Drugs were purchased from Sigma-Aldrich and tested at final water concentrations of 10-30 $\mu \mathrm{M}$, as previously described in Danio [Rihel et al., 2010b]. Video records were gathered using a standard charge-coupled device camera and a Noldus MPEG recorder (v2.1; Noldus IT). Video was subsequently processed using Ethovision XT 7.1 (Noldus IT). Tracking parameters were consistent with those previously used (Duboué et al., 2011): Parameters for detection were set as follows: 
method set to dynamic subtraction; detection set to subject brighter than background and brightness contrast from 20 to 255; current frame weight set to 15 ; video sample rate set to 29.97 , and pixel smoothing turned off. Data was subsequently processed using custom-written MATLAB scripts (Mathworks, Natick, Mass., USA). In accordance with previous experiments in A. mexicanus surface and cave fry, 1 min of complete immobility was defined as sleep [Duboue et al., 2011; Prober et al., 2006; Yokogawa et al., 2007]. For all experiments, $n \geq 10$ per group.

\section{Brain Dissection and Analysis}

Ten- or twenty-two-dpf A. Mexicanus surface and Pachón cave morphs were anesthetized in tricaine solution, and entire brains were removed in PBS and fixed in $4 \%$ formaldehyde, PBS, and $0.2 \%$ Triton-X 100 for $60 \mathrm{~min}$. Brains were incubated overnight at $4{ }^{\circ} \mathrm{C}$ in 1:1,000 polyclonal rabbit-anti-TH (AB152; Millipore). Brains were then incubated in 1:800 Alexa goat anti-rabbit (Invitrogen, Carlsbad, Calif., USA) for $90 \mathrm{~min}$ at room temperature and then mounted in Vectashield (VectorLabs) and imaged on a Zeiss SP5 confocal microscope (Manheim, Germany). Brains were imaged in 1.5- $\mu \mathrm{m}$ sections and are presented as the Z-stack projection through the entire brain. The TH-positive cell numbers were counted manually by examining individual sections in Fiji imaging software. The number of cells per cluster represents the average of surface $n \geq 12$, Pachón cave $n \geq 10$ (10 dpf), and surface $n \geq 4$, Pachón $n \geq 8$ (22 dpf).

\section{Statistics}

For drug screens, multivariate ANOVA tests were carried out to test the effects of drug, genotype, and the drug* genotype interaction. Significant drug*genotype interaction $(\mathrm{p}<0.05)$ revealed drugs that differentially affected sleep between surface and cave forms. The $\mathrm{F}$ statistic and $\mathrm{p}$ values for these tests are given in figures 1 and 3. For detailed analysis of propranolol (fig. 2b-e), we implemented a Kruskal-Wallis one-way ANOVA. When significance was detected, we followed with a multiple comparisons post-test correcting for the number of comparisons made. For cell counting, pairwise comparisons were carried out using a nonparametric t test (fig. 4j, k). All statistical analyses were implemented in the R Language for Statistical Computing [Team RDC, 2011].

\section{Results}

To identify the biological basis for reduced sleep in cavefish populations, we screened putative arousal system antagonists for drugs that selectively promote sleep in cavefish. We reasoned that blockade of a signaling pathway involved in evolutionarily derived sleep loss would have little effect on sleep in surface populations while increasing sleep in cavefish. We tested antagonists directed toward glutamatergic, seretonergic, histaminergic, cholinergic, dopaminergic, and noradrenergic systems that have previously been implicated in sleep [Cirelli, 2009; Hunsley et al., 2006; Parmentier et al., 2002;
Pollock and Mistlberger, 2003; Simon et al., 2011; Stone et al., 1992; Wisor et al., 2003] (fig. 1a). We found that the NMDA receptor antagonist MK-801 as well as the $\beta$-adrenergic antagonist propranolol (P0884; Sigma Chemical Co., St. Louis, Mo., USA) potently increased sleep in Pachón cavefish while having little effect on surface fish (fig. 1a). The tyrosine hydroxylase (TH) inhibitor 3-iodoL-tyrosine disrupts synthesis of dopamine and norepinephrine approached significance $(p=0.06)$. Because of a known role for noradrenergic neurons of the ascending reticular activating system (ARAS) in sleep-wake regulation, we focused on the role of propranolol on sleep [Berridge and Foote, 1991]. Propranolol is a general inhibitor of $\beta$-adrenergic receptors that has been previously reported to modulate sleep in Danio and mammals [Mendelson et al., 1980; Rihel et al., 2010a; Whitehurst et al., 1999]. Furthermore, norepinephrine is an important component of the wake-promoting ascending reticular activating system [Berridge and Foote, 1991]. A dose-response curve for propranolol in concentrations ranging from $10^{-9} \mathrm{M}$ through $10^{-4} \mathrm{M}$ resulted in a concentrationdependent increase in sleep in the cavefish population (fig. 1b). There was no significant effect at any dose in surface populations. Because cavefish sleep loss could result from inadequate sleep-promoting effects, we wanted to explore the role of gamma-aminobutyric acid (GABA) signaling, a primary sleep-promoting system in vertebrates. We tested the GABA-A receptor antagonist bicuculine and found that it did not affect sleep in cave or surface populations at any dose tested (fig. 1c), indicating that the diminished sleep in cave populations is due to an increase in wake-promoting signaling rather than altered sleep-inducing signaling.

Quantification of total sleep reveals that surface fish sleep significantly more than cave populations, as has previously been reported [Duboue et al., 2011]. Propranolol has no effect on sleep in surface fish, while it significantly increases sleep in cavefish (fig. 1a, b, 2a, b). These findings suggest that increased $\beta$-adrenergic signaling confers sleep loss in cave populations. We next quantified activity per waking minute to determine whether propranolol induces consolidated periods of sleep. In agreement with previous findings, surface and cavefish show similar activity per waking minute. Treatment with propranolol results in no change in waking activity for both cave and surface fish. Total quantification showed no significant differences for both daytime $(\mathrm{p}=0.50)$ and nighttime ( $\mathrm{p}=0.82$ ) waking activity (fig. $2 \mathrm{c})$. Thus, it is likely that propranolol treatment leads to increased sleep rather than affecting motor function. 


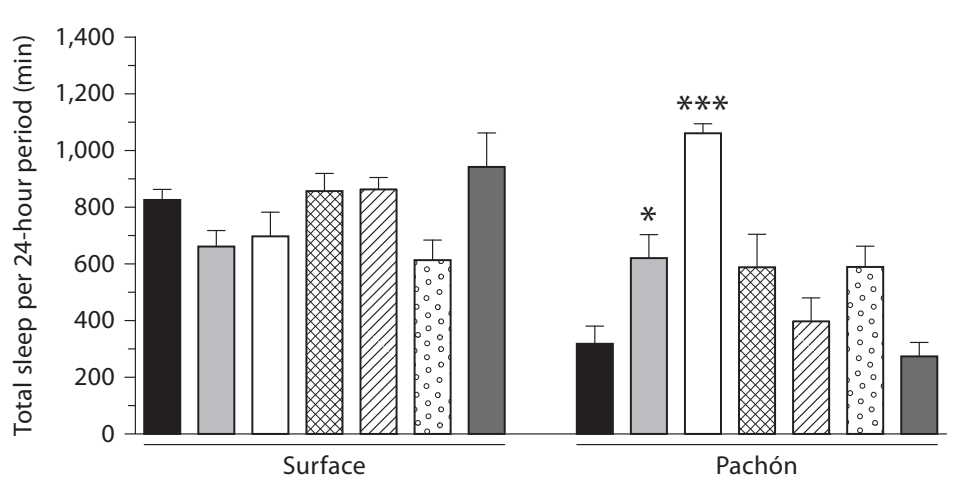

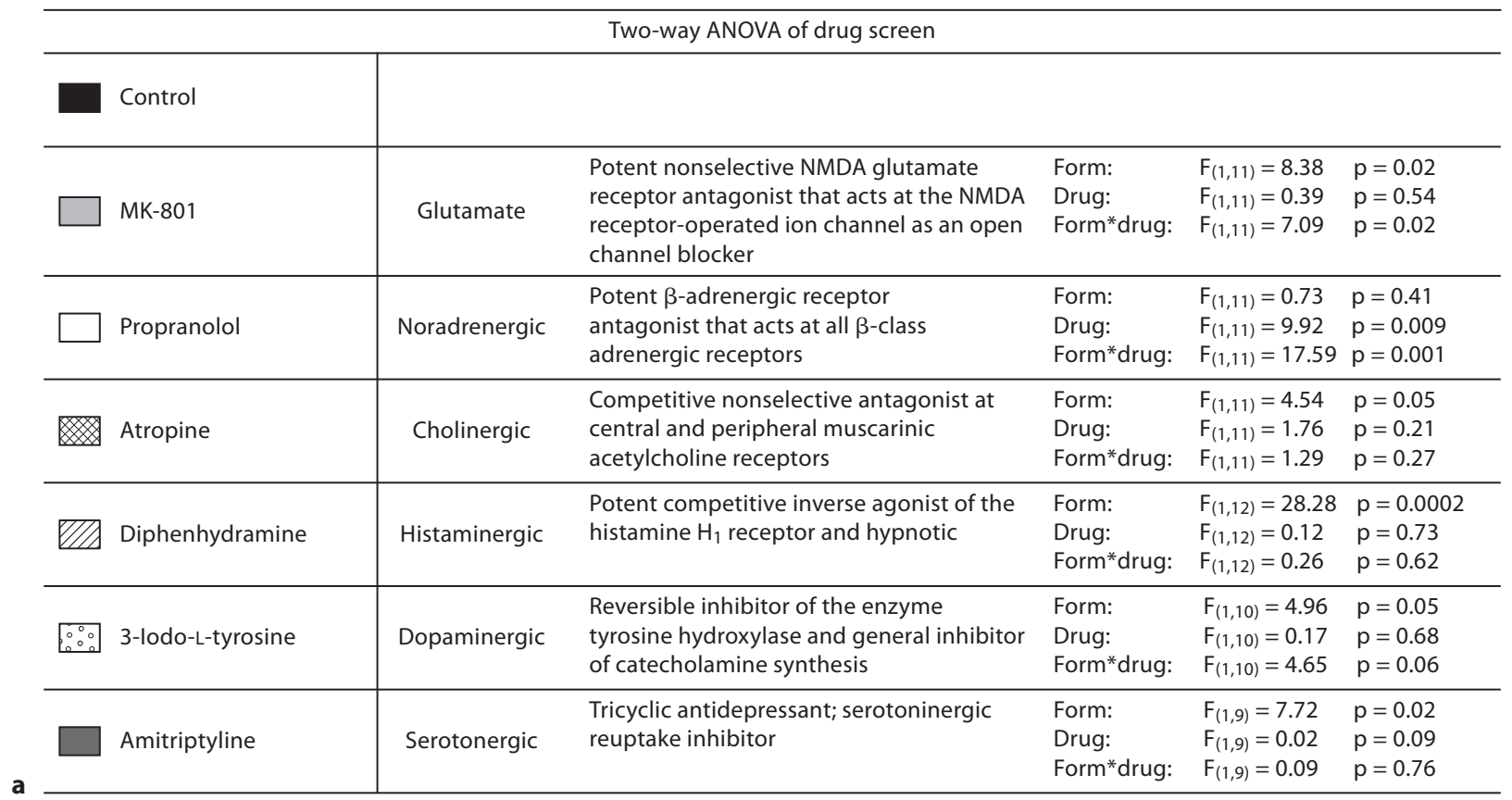

Fig. 1. Propranolol and MK-801 increase sleep in Pachón cavefish. a The effects of six drugs targeting neurotransmitter systems were assayed at a $30-\mu \mathrm{M}$ concentration for $24 \mathrm{~h}$. The total minutes of sleep per 24-hour period reveal no effect of any drug on surface populations while propranolol and MK-801 significantly increased sleep in Pachón cavefish. The mean total sleep times for control surface and Pachón were $846 \pm 37.2 \mathrm{~min}$ and $318 \pm 62.57$ min, respectively, and they were significantly different as previously reported (two-tailed Mann-Whitney U test, p < 0.01). Val-

Sleep consists of individual sleep bouts. We previously reported that reduced sleep in cave populations was due to shortened lengths of individual sleep bouts rather than changes in bout number [Duboue et al., 2011]. We measured the effect of propranolol on the number and length of individual sleep bouts. Propranolol dramatically in- ues for drug-treated groups were as follows: MK801: surface = $662.2 \pm 55.46$ min, Pachón $=620.9 \pm 83.19$ min; propranolol: surface $=697.9 \pm 84.65 \mathrm{~min}$, Pachón $=1,061.0 \pm 33.41 \mathrm{~min}$; atropine: surface $=857.0 \pm 62.88 \mathrm{~min}$, Pachón $=589.1 \pm 115.5 \mathrm{~min}$; diphenhydramine: surface $=863.5 \pm 42.3 \mathrm{~min}$, Pachón $=398.1$ $\pm 82.9 \mathrm{~min}$; 3 -iodo-L-tyrosine: surface $=613.9 \pm 70.8 \mathrm{~min}$, Pachón $=589.4 \pm 73.0 \mathrm{~min}$; amitriptyline: surface $=942.5 \pm$ $120.2 \mathrm{~min}$, Pachón $=273.6 \pm 49.5 \mathrm{~min}$. Two-way ANOVA F and $\mathrm{p}$ values are shown. 


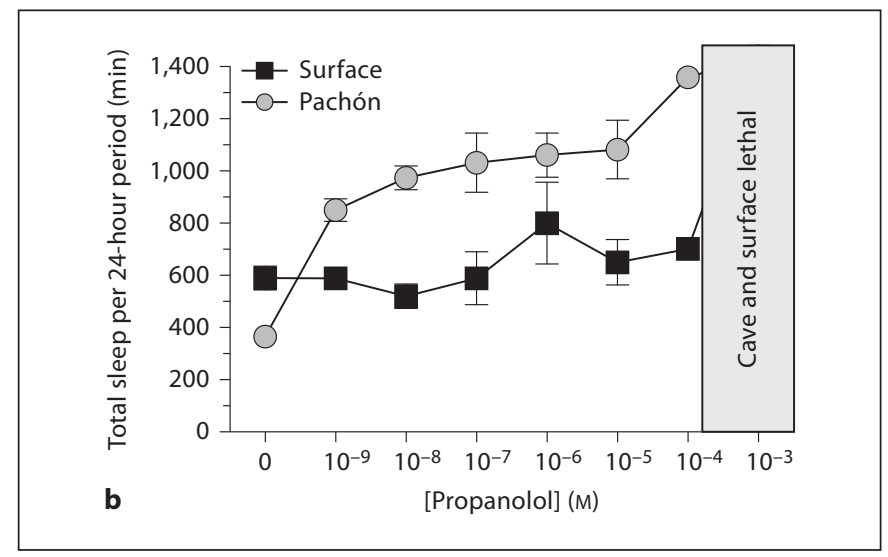

Fig. 1. Propranolol and MK-801 increase sleep in Pachón cavefish. b A dose-response curve for total sleep time in propranolol-treated fish revealed a dose-dependent increase in sleep in Pachón cave populations and no effect at any dose in surface fish. The total sleep (mean \pm SEM) times for the dose-response curve and statistical analysis (two-tailed nonparametric t test) relative to the control $(0 \mu \mathrm{M})$ were as follows: surface (control $=589.4 \pm 45.6$ $\min ; 10^{-9} \mu \mathrm{M}=588.0 \pm 35.8 \mathrm{~min}, \mathrm{p}=0.36 ; 10^{-8} \mu \mathrm{M}=520.0 \pm$ $46.9 \min , \mathrm{p}=0.12 ; 10^{-7} \mu \mathrm{M}=589.0 \pm 101.5 \mathrm{~min}, \mathrm{p}=0.13 ; 10^{-6}$ $\mu \mathrm{M}=800.0 \pm 156.4 \mathrm{~min}, \mathrm{p}=0.24 ; 10^{-5} \mu \mathrm{M}=650.0 \pm 86.9 \mathrm{~min}$, $\mathrm{p}=0.57 ; 10^{-4} \mu \mathrm{M}=701.0 \pm 26.4 \mathrm{~min}, \mathrm{p}=0.21,10^{-3} \mu \mathrm{M}=$ lethal $)$ and Pachón (control $=365.7 \pm 14.6 \mathrm{~min} ; 10^{-9} \mu \mathrm{M}=850.0 \pm 43.2$ $\min , \mathrm{p}<0.001 ; 10^{-8} \mu \mathrm{M}=974.2 \pm 45.7 \mathrm{~min}, \mathrm{p}<0.001 ; 10^{-7} \mu \mathrm{M}=$ $1,031.7 \pm 113.4 \mathrm{~min}, \mathrm{p}<0.001 ; 10^{-6} \mu \mathrm{M}=1,061.0 \pm 84.89 \mathrm{~min}$, $\mathrm{p}<0.001 ; 10^{-5} \mu \mathrm{M}=1,082.3 \pm 112.4 \mathrm{~min}, \mathrm{p}<0.001 ; 10^{-4} \mu \mathrm{M}=$ $1,359.0 \pm 40.2 \mathrm{~min}, \mathrm{p}<0.001 ; 10^{-3} \mu \mathrm{M}=$ lethal). $\mathrm{c}$ At all doses

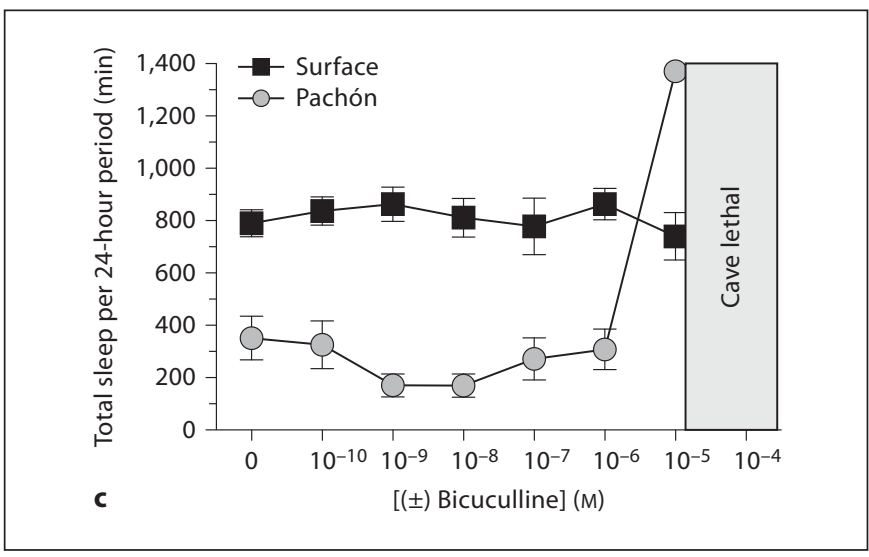

tested the GABA-A receptor antagonist bicuculine failed to effect sleep in cave and surface populations. Bicuculine induced lethality in cave populations at concentrations that did not affect surface fish. Total sleep (mean \pm SEM) times for the dose-response curve and statistical analysis (two-tailed nonparametric $t$ test) relative to the control $(0 \mu \mathrm{M})$ were as follows: surface (control $=790.2 \pm$ $51.9 \mathrm{~min} ; 10^{-10} \mu \mathrm{M}=837.2 \pm 53.6 \mathrm{~min}, \mathrm{p}=0.61 ; 10^{-9} \mu \mathrm{M}=862.8$ $\pm 65.6 \mathrm{~min}, \mathrm{p}=0.45 ; 10^{-8} \mu \mathrm{M}=811.5 \pm 73.6 \mathrm{~min}, \mathrm{p}=0.83 ; 10^{-7}$ $\mu \mathrm{M}=778.0 \pm 107.7 \mathrm{~min}, \mathrm{p}=0.92 ; 10^{-6} \mu \mathrm{M}=863.1 \pm 59.7 \mathrm{~min}$, $\mathrm{p}=0.041 ; 10^{-5} \mu \mathrm{M}=740.2 \pm 90.3 \mathrm{~min}, \mathrm{p}=0.66 ; 10^{-4} \mu \mathrm{M}=808.7$ $\pm 140.5 \mathrm{~min}, \mathrm{p}=0.91$ ) and Pachón (control = 351.4 $\pm 83.7 \mathrm{~min}$; $10^{-10} \mu \mathrm{M}=325.5 \pm 91.2 \mathrm{~min}, \mathrm{p}=0.83 ; 10^{-9} \mu \mathrm{M}=170.5 \pm 43.5$ $\min , \mathrm{p}=0.08 ; 10^{-8} \mu \mathrm{M}=170.0 \pm 44.7 \mathrm{~min}, \mathrm{p}=0.08 ; 10^{-7} \mu \mathrm{M}=$ $271.8 \pm 80.4 \mathrm{~min}, \mathrm{p}=0.50 ; 10^{-6} \mu \mathrm{M}=308.3 \pm 77.2 \mathrm{~min}, \mathrm{p}=0.71$; $10^{-5} \mu \mathrm{M}=$ lethal; $10^{-4} \mu \mathrm{M}=$ lethal). All graphs represent means \pm SEM. ${ }^{*} \mathrm{p}<0.05 ;{ }^{* * *} \mathrm{p}=0.001$.

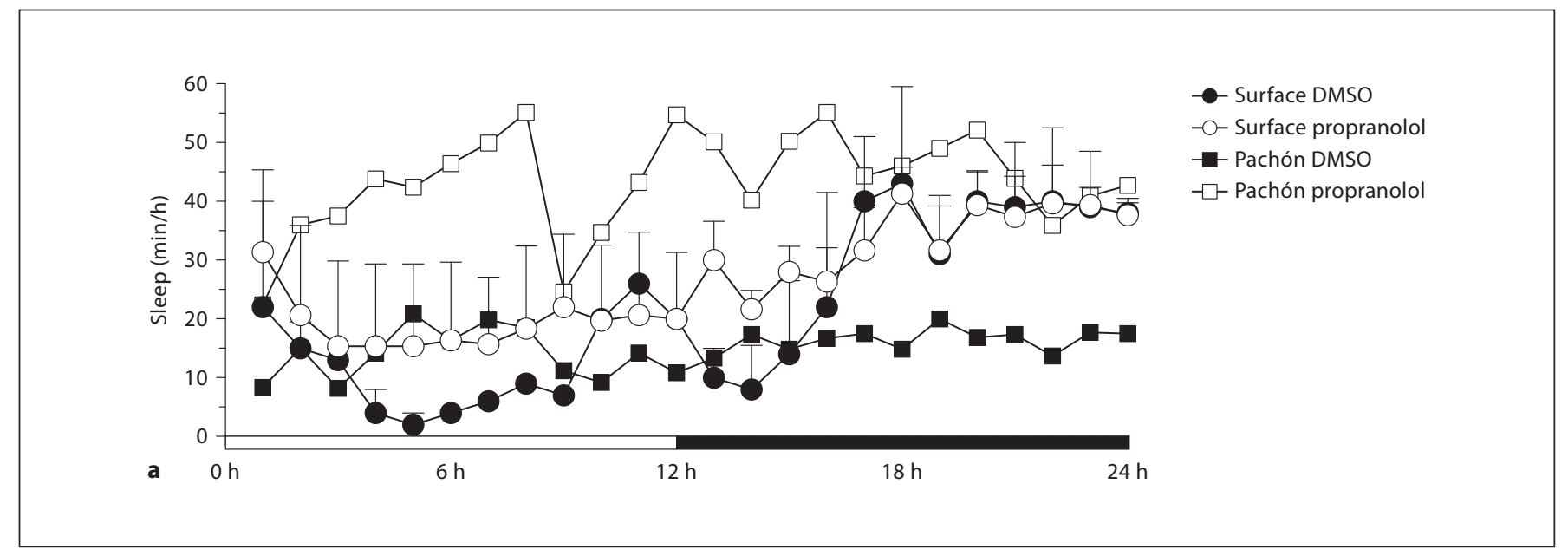

Fig. 2. Propranolol selectively increases sleep bout duration in Pachón cavefish. a After an 18-hour acclimation period, both surface and Pachón cavefish treated with either DMSO or $30 \mu \mathrm{M}$ propranolol were assayed for sleep over a 24-hour period. 

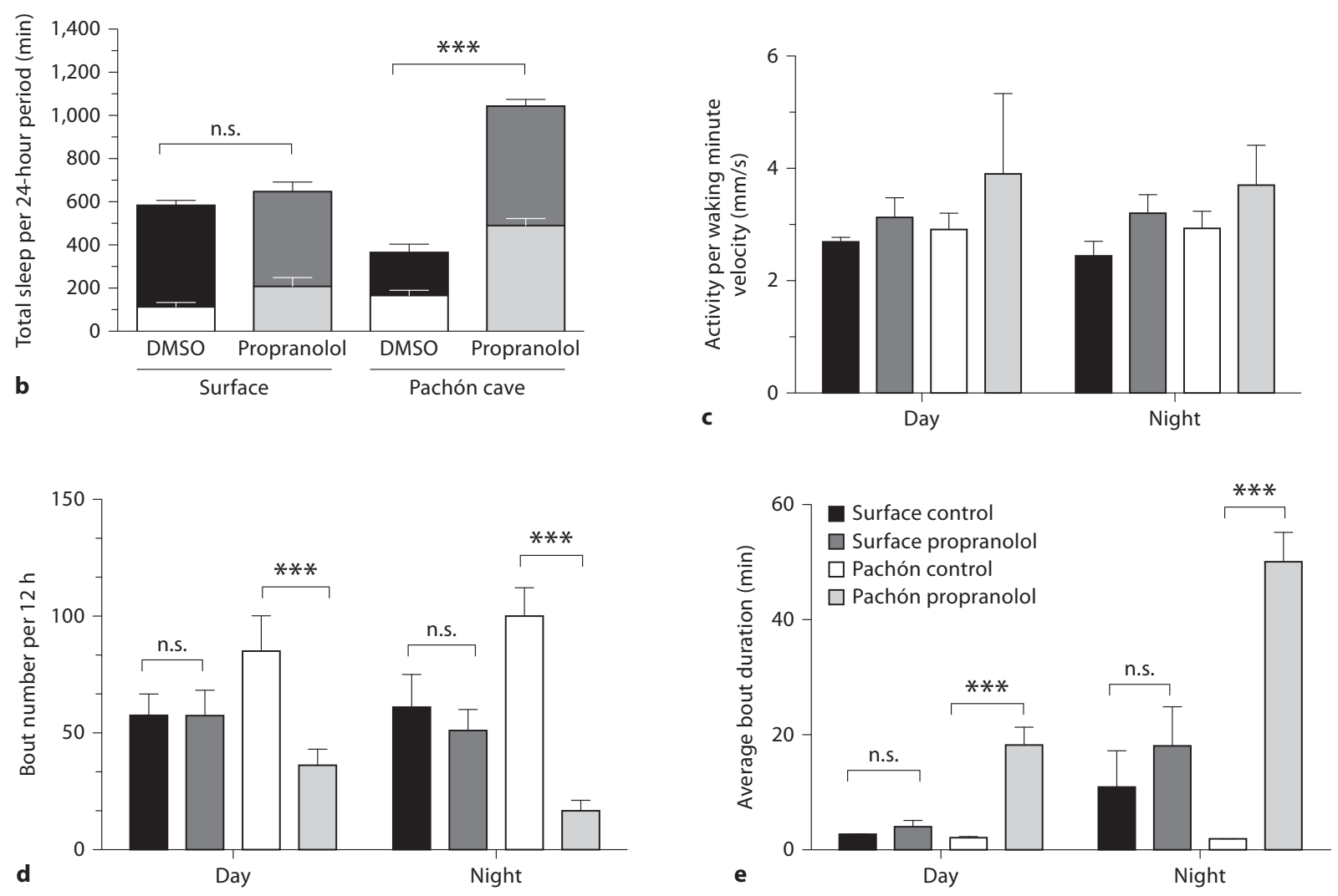

Fig. 2. Propranolol selectively increases sleep bout duration in Pachón cavefish. b Propranolol significantly increased the total sleep over a 24-hour day in Pachón cavefish compared to controls (DMSO: $1,041 \pm 38.21 \mathrm{~min}$; propranolol $318 \pm 40.8 \mathrm{~min} ; \mathrm{p}<$ 0.0001) while having little effect on surface fish (DMSO: $582 \pm$ 48.64 min; propranolol: $646.1 \pm 85.75$ min; $p>0.05)$. c Quantification of activity per waking minute (scored as average $\mathrm{mm} / \mathrm{s}$ velocity) suggests no significant difference among groups for either daytime [ANOVA, $\mathrm{H}_{(30,4)}=2.345, \mathrm{p}=0.50$ ] or nighttime [ANOVA, $\mathrm{H}_{(30,4)}=0.9424, \mathrm{p}=0.81$ ]. Waking activities were as follows: daytime: surface DMSO $=2.44 \pm 0.08 \mathrm{~mm} / \mathrm{s}$; surface propranolol $=3.12 \pm 0.35 \mathrm{~mm} / \mathrm{s}$; cave $\mathrm{DMSO}=2.91 \pm 0.29$ $\mathrm{mm} / \mathrm{s}$; cave propranolol $=3.99 \pm 0.59 \mathrm{~mm} / \mathrm{s}$; nighttime: surface $\mathrm{DMSO}=2.69 \pm 0.08 \mathrm{~mm} / \mathrm{s}$; surface propranolol $=3.20 \pm 0.33$ $\mathrm{mm} / \mathrm{s}$; cave DMSO = $2.94 \pm 0.30 \mathrm{~mm} / \mathrm{s}$; cave propranolol $=$ $3.76 \pm 0.71 \mathrm{~mm} / \mathrm{s}$. d Quantification of the number of bouts revealed a significant difference among groups for daytime [Kruskal-Wallis ANOVA, $\left.\mathrm{H}_{(30,4)}=7.712, \mathrm{p}<0.05\right]$ and nighttime bout numbers [Kruskal-Wallis ANOVA $\mathrm{H}_{(30,4)}=16.99, \mathrm{p}>0.001$ ]. a, b Black and dark grey bars denote surface, white and light grey bars denote Pachón. Dark grey and light grey bars denote drug- treated groups. A post hoc Dunn's multiple comparisons test revealed that propranolol reduces daytime (DMSO: $36.2 \pm 6.8$ bouts; propranolol: $85.0 \pm 15.2$ bouts, $\mathrm{p}<0.001)$ and nighttime (DMSO: $100 \pm 12.2$ bouts; propranolol: $16.7 \pm 4.5$ bouts, $p<$ 0.001 ) bout numbers in cave populations while having no significant effect on bout number in surface fish (daytime - DMSO: 57.5 \pm 9.2 bouts; propranolol: $57.4 \pm 10.9$ bouts; nighttime - DMSO: $61.0 \pm 14.0$ bouts; propranolol: $51.1 \pm 8.9$ bouts; $p>0.05$ for both). e Quantification of the average bout duration revealed a significant difference among groups for daytime [Kruskal-Wallis ANOVA, $\mathrm{H}_{(30,4)}=20.02$, $\left.\mathrm{p}<0.001\right]$ and nighttime bout numbers [Kruskal-Wallis ANOVA $\mathrm{H}_{(30,4)}=17.87, \mathrm{p}>0.001$ ]. A post hoc Dunn's multiple comparisons test revealed that propranolol increased the average daytime (DMSO: $2.12 \pm 0.27 \mathrm{~min}$; propranolol: $18.21 \pm 3.1 \mathrm{~min}, \mathrm{p}<0.001)$ and nighttime (DMSO: $1.92 \pm 0.2$ min; propranolol: $70.1 \pm 50.1 \mathrm{~min}, \mathrm{p}<0.001)$ bout duration in cave populations while having no significant effect on bout number in surface fish (daytime - DMSO: $2.73 \pm 0.5 \mathrm{~min}$; propranolol: $4.03 \pm 1.1 \mathrm{~min}$; nighttime - DMSO: $10.92 \pm 6.3 \mathrm{~min}$; propranolol: $18.07 \pm 6.8$ bouts; $\mathrm{p}>0.05$ for both). 


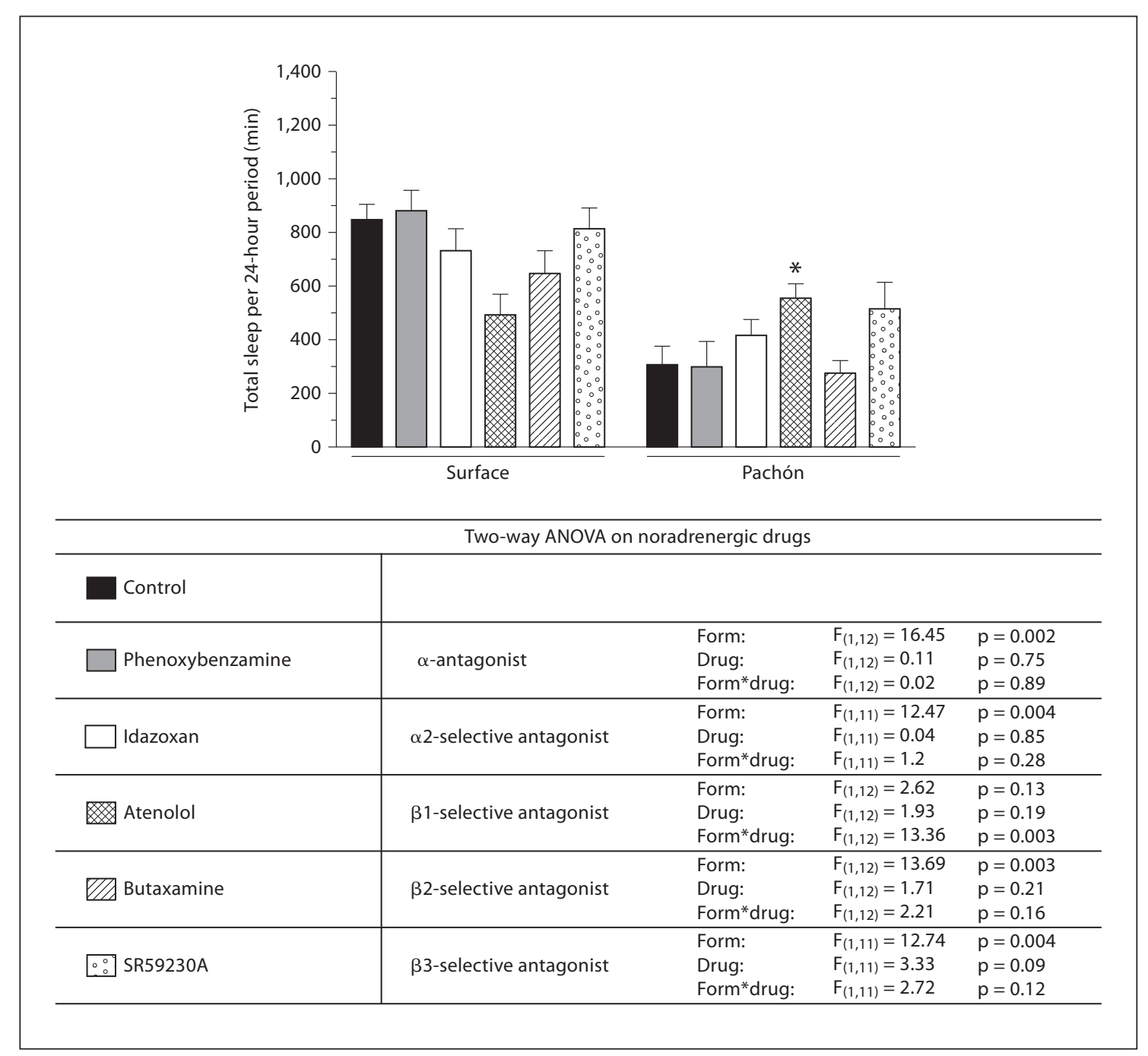

Fig. 3. Propranolol selectively increases sleep bout duration in Pachón cavefish. The three $\beta$-adrenergics ( $\beta 1$-atenolol, $\beta 2$-butaxamine, and $\beta 3$-SR59203A) did not increase sleep in surface populations, consistent with the lack of effect observed for propranolol. A significant increase in cavefish sleep was observed with the $\beta 1$ antagonist atenolol, suggesting that $\beta 1$-adrenergic receptors regulate evolutionarily derived sleep loss. No effect of the $\alpha$-adrenergic antagonists phenoxybenzamine and idazoxan was observed in cave or surface populations. The mean total sleep times for control surface and Pachón fish were $842.3 \pm 63.4$ min and $319.0 \pm$

tions. In vertebrates, norepinephrine signals through $\alpha$ adrenergic receptors and $\beta$-adrenergic receptors. We assayed drugs that specifically targeted $\alpha$-adrenergic and $\beta$-adrenergic subtypes. There was no effect with the $\alpha$ adrenergic antagonist phenoxybenzamine or the $\alpha 2$-adrenergic antagonist idazoxan suggesting the rescue effect of propranolol was specific to $\beta$-adrenergic receptors (fig. 3). While the Danio genome encodes for four $\beta$-ad-
$62.6 \mathrm{~min}$, respectively, and they were significantly different as previously reported (two-tailed Mann-Whitney U test, $\mathrm{p}<0.01$ ). Values for drug-treated groups were as follows: phenoxybenzamine: surface $=877.3 \pm 80.02 \mathrm{~min}$, Pachón $=301.2 \pm 94.78 \mathrm{~min}$; idazoxan: surface $=728.4 \pm 86.3 \mathrm{~min}$, Pachón $=413.2 \pm 61.82$ min; atenolol: surface $=493.2 \pm 76.08$ min, Pachón $=555.5 \pm$ 52.01 min; butaxamine: surface $=644.9 \pm 88.49$ min, Pachón $=$ $274.8 \pm 47.29 \mathrm{~min} ;$ SR59230A: surface $=808.0 \pm 82.92 \mathrm{~min}$, Pachón $=515.4 \pm 98.58 \mathrm{~min}$. Two-way ANOVA $\mathrm{F}$ and $\mathrm{p}$ values are shown.

renergic receptors [Ruuskanen et al., 2004], the number of $\beta$-adrenergic receptor genes in the $A$. mexicanus genome remains unknown. To gain insight into the subclass of $\beta$-adrenergic receptors modulating sleep, we assayed the effects of subtype-specific $\beta$-adrenergic antagonists on sleep. The three $\beta$-adrenergic antagonists ( $\beta 1$-atenolol, $\beta 2$-butaxamine, and $\beta 3$-SR59203A) did not affect sleep in surface populations, consistent with the 


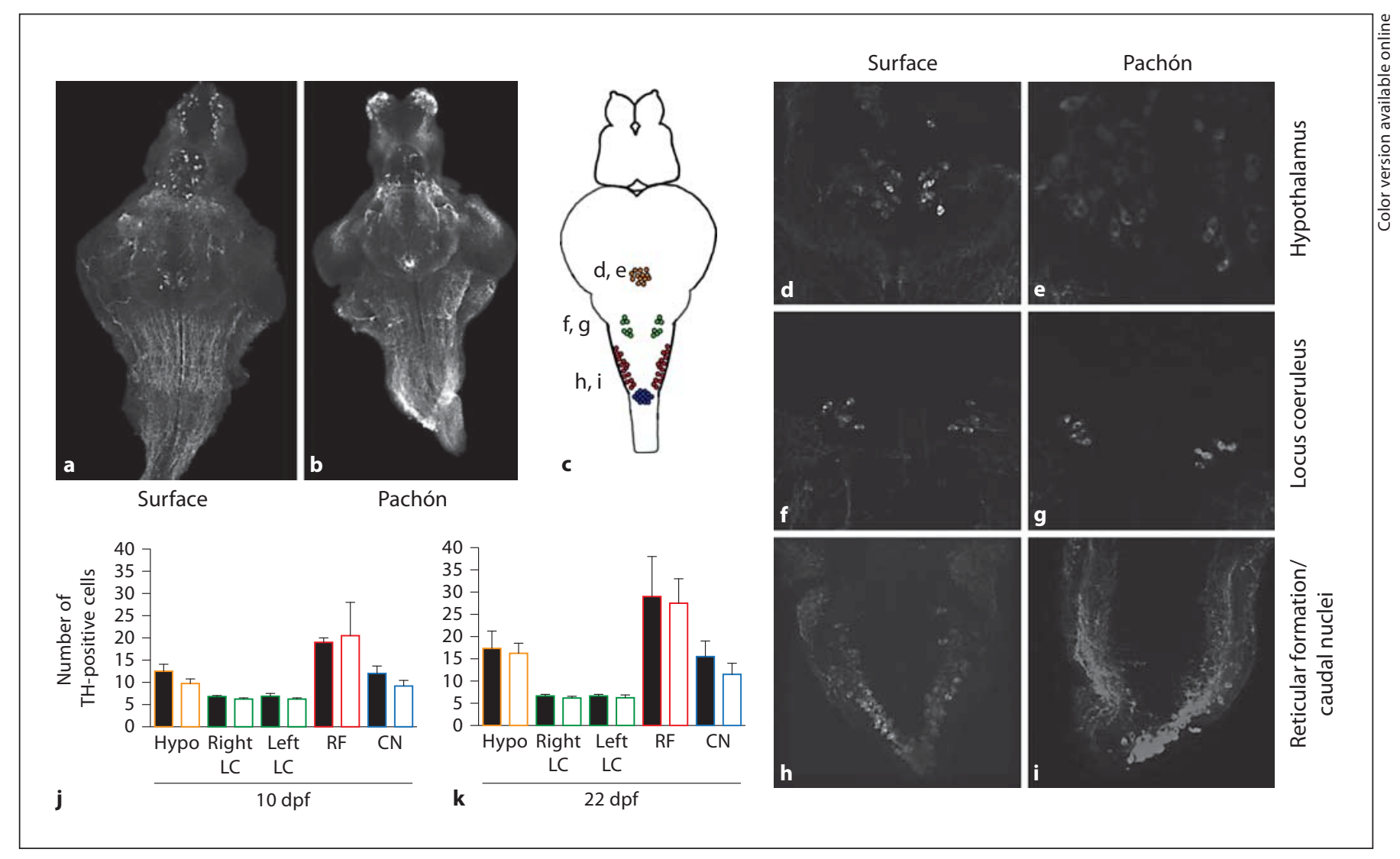

Fig. 4. Propranolol reduces the sleep bout number and increases the average sleep bout length in Pachón cavefish. a, b Whole mount projection of 10-dpf surface (a) and cavefish (b) brains stained with anti-TH alongside. Scale bars represent $200 \mu \mathrm{M}$. c Diagram depicting cell bodies of catecholamine regions quantified. Orange: hypothalamus (Hypo), green: right and left locus coeruleus (rLC and lLC), red: reticular formation (RF), blue: cau-

lack of effect observed for propranolol. A significant increase in cavefish sleep was observed with the $\beta 1$-antagonist atenolol, suggesting that $\beta 1$-adrenergic receptors regulate evolutionarily derived sleep loss. Cavefish treated with the $\beta 3$-antagonist SR59203A approached a significant increase in sleep, raising the possibility that a combination of $\beta 1$ and $\beta 3$ signaling results in reduced sleep in Pachón populations (fig. 3).

We next asked how $\beta$-adrenergic signaling affected sleep. It is possible that reduced sleep in cave populations results from neuroanatomical changes such as an increased number of noradrenergic neurons or increased innervations of targets. This notion is supported by the differential distribution of catecholaminergic cell bodies among various fish species [Brinon et al., 1998]. Alternatively, subtle changes in neural function may underlie the dal nuclei $(\mathrm{CN})$. $\mathbf{d}-\mathbf{i}$ Single $1.5-\mu \mathrm{M}$ sections were used to quantify the number of TH-positive cells within surface $(\mathbf{d}, \mathbf{f}, \mathbf{h})$ and cavefish brains $(\mathbf{e}, \mathbf{g}, \mathbf{i})$. Scale bars represent $50 \mu \mathrm{M}$. d, e Hypothalamus. $\mathbf{f}, \mathbf{g}$ Locus coeruleus. $\mathbf{h}$, i Reticular formation and caudal nuclei. $\mathbf{j}$, $\mathbf{k}$ Total quantification of TH-positive cells revealed no significant difference among groups ( $\mathrm{p}>0.05$ for all groups) for $10 \mathrm{dpf}(\mathbf{j})$ and $22 \mathrm{dpf}(\mathbf{k})$. All bars represent means \pm SEM.

dramatic reduction in sleep observed in cave populations. The enzyme $\mathrm{TH}$ is an obligate precursor for the synthesis of all catecholamine. In Danio, two TH genes (Th1 and Th2) are expressed in neural clusters of the olfactory bulb, forebrain, hypothalamus, and hindbrain [Jang et al., 2011; Prober et al., 2006; Yamamoto et al., 2011; Yamamoto and Vernier, 2011]. We found that antimouse TH labels $A$. mexicanus brains in an expression pattern similar to the known pattern observed in Danio, suggesting conservation between the two systems.

For neuroanatomical analysis we imaged 10-dpf fry because brains at this stage are small enough for wholemount confocal microscopy. Additionally, we used 22dpf fry that match the age of fish used for behavioral analysis. Ten-dpf juvenile surface and cave morphs were dissected and stained with anti-TH. Immunostaining of the 
surface and cavefish brain revealed that catecholamine cell bodies and projections are highly conserved with those previously reported in Danio rerio in both 10-dpf (fig. 4a-c) and 22-dpf fry (online suppl. fig. 1, see www. karger.com/doi/10.1159/000341403 for all online suppl. material). The number of catecholamine-positive cell bodies were quantified in all clusters including those of the hypothalamus [Prober et al., 2006], locus coeruleus [Filippi et al., 2010], reticular formation, and caudal nuclei [Berger, 1969; Moruzzi and Magoun, 1949] in order to test whether an altered number of catecholamine neurons are present in cave populations (fig. $4 \mathrm{~d}-\mathrm{k}$ ). No significant differences were observed in any clusters of 10 and 22-dpf fry, suggesting that the gross morphology of catecholamine neurons is conserved between cave and surface populations (fig. $4 \mathrm{j}, \mathrm{k}$ ). To our knowledge, these findings represent the first analysis of central brain circuitry in cavefish and reveal an anatomical conservation of the catecholamine systems between $\operatorname{distinct} A$. mexicanus morphs. These results suggest that catecholamine function, rather than neuroanatomical changes, underlie evolutionarily derived sleep loss.

\section{Discussion}

A. mexicanus cave populations appear to be uniquely adapted to life in a nutrient-poor environment. In addition to reduced sleep, cavefish display a number of traits that are adaptive to nutrient-poor environments including lower basal metabolic rates and a heightened attraction to vibration [Ercolini et al., 1987; Salin et al., 2010; Yoshizawa et al., 2010]. We previously reported that the reduced sleep in cave populations is due to shortened sleep bout duration. Here we extend these observations through pharmacological interrogation of sleep-wake regulation in A. mexicanus. We identified the NMDA receptor antagonist MK-801 and the $\beta$-adrenergic antagonist propranolol as increasing sleep selectively in cave populations, suggesting that blockade of $\beta$-adrenergic receptors in cave populations induces surface fish-like sleep. Further characterization of $\beta$-adrenergic signaling reveals a role for $\beta 1$-adrenergic receptors, but not $\beta 2$ - or $\alpha$-adrenergic receptors, in evolutionarily derived sleep loss. This finding suggests that the noradrenergic wakepromoting system is finely tuned in both cave and surface A. mexicanus in accordance with their natural ecology, and that noradrenergic antagonists in cavefish may act to mimic a neural system of sleep consolidation seen in $A$. mexicanus surface conspecifics. It is possible that $\beta$-ad- renergic signaling generally modulates metabolism or hunger-induced behaviors. Alternatively, differences in $\beta$-adrenergic signaling may be specific to sleep. Future examination of the effects of propranolol on cavefish metabolism and foraging behaviors will allow differentiation between these two possibilities.

We performed a detailed neuroanatomical analysis of $\mathrm{TH}$-immunoreactive cells in both morphs. The finding of conserved catecholamine neuroanatomy in surface and cave morphs suggests that the differential effects of propranolol are likely due to altered $\beta$-adrenergic signaling. While there are no obvious differences in projections of catecholamine neurons, it is possible that subtle changes in synaptic connectivity are responsible for the increased wakefulness in cave populations. Alternatively, increased epinephrine/norepinephrine release or increased signaling may be responsible for the effects of propranolol. Future experiments quantifying epinephrine/norepinephrine levels and release in surface populations may be informative.

Our findings that blockade of $\beta$-adrenergic receptors selectively rescues sleep in cave populations suggest an evolutionarily derived increase in arousal systems in cave populations. It is also possible that decreased sensitivity of sleep-promoting systems modulates reduced sleep in cave populations. Activation of GABA-A receptors and adenosine have been shown to modulate sleep in other systems [Basheer et al., 2004; Tobler et al., 2001]. Future work examining the effects of benzodiazepines and adenosine on sleep in cave populations will help to identify the role of sleep-promoting systems in evolutionarily derived sleep loss.

Both the functions and the evolutionary basis of sleep have been the subject of great debate [Lesku et al., 2006]. Sleep has been suggested to be a state of adaptive inactivity derived from a more general rest-like state, and it has been suggested that the ecological factors in which species live serve as a driving force impacting sleep need [Allada and Siegel, 2008]. The differences in habitat between surface and cave populations present a unique opportunity to examine the effects of ecology and evolutionary history on sleep. Our findings provide the first insight into the biological basis of reduced sleep in cave populations.

It is likely that the mechanisms underlying sleep-wake regulation in cavefish extend to affect a number of processes beyond sleep. Studies in the Somalian blind cavefish (P. Andruzzi) reveal that these fish have retained a circadian clock but lost the ability to respond to light and temperature, which is likely an adaptation to perpetual darkness and near constant temperature in the cave en- 
vironment. The fish are capable of generating free-running 47-hour rhythms in response to feeding [Cavallari et al., 2011]. Feeding entrainment has been observed in Danio, suggesting that this process is conserved in terranean and subterranean fish populations [Lopez-Olmeda et al., 2010]. It will be of great interest to determine whether A. mexicanus, like $P$. andruzzi, can generate food-entrained circadian rhythms.

Foraging requires alterations in a number of behaviors including decreased sleep and increased activity. There are a number of feeding-related behaviors that differ between cave and surface $A$. mexicanus. It will be important to determine whether $\beta$-adrenergic signaling selectively regulates sleep or generally regulates feeding-associated behaviors. A. mexicanus cave morphs differ in feeding behavior from surface morphs. Cavefish approach food at a $45^{\circ}$ angle, while surface morphs approach food vertically [Schemmel, 1980]. It is suggested that the diminished angle of food approach is an adaptation for a slower food approach in cavefish. The altered approach was found to be recessive and segregation analysis in F2 surface-cave hybrids suggests surface-cave differences in approach are mono-allelic; however, the gene involved has not been identified [Schemmel et al., 1980]. Reduced sleep in cave populations is dominant [Duboue et al., 2011], supporting the notion that changes in sleep and feeding angle are controlled by distinct genetic mechanisms.

Fish detect food sources through vibration in the water, and one manifestation of foraging in A. mexicanus is vibration attraction behavior (VAB). Cavefish appear to be specifically tuned to detect water droplets at $35 \mathrm{~Hz}$, the approximate frequency generated from a water droplet falling from a cave ceiling [Yoshizawa et al., 2010]. The increased sensitivity to vibrations in the water may allow animals to locate prey in the cave environment. Evidence suggests that VAB is directly related to foraging capabilities. Prey capture experiments have found that cave populations with increased VAB outcompete surface fish in the dark [Yoshizawa et al., 2010]. Testing the effects of propranolol on VAB will provide insight into whether similar molecular mechanisms underlie the evolutionarily derived changes in sleep and feeding behavior.

Taken together, we have provided insight into the molecular basis for evolutionarily derived sleep loss in the Mexican cavefish. We show that that sleep loss in the Pachón cavefish can be rescued by blockade of $\beta$-adrenergic or NMDA receptors. Future studies examining additional feeding-related behaviors will examine whether $\beta$-adrenergic signaling is a general regulator of feedingassociated behaviors. These studies will provide critical insight into the evolutionary basis for behavioral changes of subterranean fish.

\section{Acknowledgments}

The authors are grateful to Dr. Wolf Huetteroth (University of Massachusetts Medical School) for support with anatomical analysis and Drs. Grant Mastick (University of Nevada, Reno), Masato Yoshizawa (University of Maryland), and Florian Razy (New York University) for critical feedback on this manuscript. This work was supported by NSF grant IOS-0821939 to RLB. This work was also supported by grants from the NCRR (5P20RR016464) and the NIGMS (8 P20 GM103440) to the University of Nevada.

\section{References}

Allada R, Siegel JM (2008): Unearthing the phylogenetic roots of sleep. Curr Biol 18:R670R679.

- Basheer R, Strecker RE, Thakkar MM, McCarley RW (2004): Adenosine and sleep-wake regulation. Prog Neurobiol 73:379-396.

Berger H (1969): On the electroencephalogram of man. Electroencephalogr Clin Neurophysiol (suppl 28):37-320.

Berridge CW, Foote SL (1991): Effects of locus coeruleus activation on electroencephalographic activity in neocortex and hippocampus. J Neurosci 11:3135-3145.

Borowsky R (2008): Handling Astyanax mexicanus eggs and fry. CSH Protoc DOI: 10.1101/ pdb.prot5093
- Brinon JG, Arevalo R, Weruaga E, Crespo C, Alonso JR, Aijon J (1998): Tyrosine hydroxylase-like immunoreactivity in the brain of the teleost fish tinca tinca. Arch Ital Biol 136: 17-44.

Burt de Perera T (2004): A study of spatial parameters encoded in the spatial map of the blind Mexican cave fish (Astyanax fasciatus). Anim Behav 68:291-295.

-Cavallari N, Frigato E, Vallone D, Frohlich N, Lopez-Olmeda JF, Foa A, Berti R, SanchezVazquez FJ, Bertolucci C, Foulkes NS (2011): A blind circadian clock in cavefish reveals that opsins mediate peripheral clock photoreception. PLoS Biol 9:e1001142.

Cirelli C (2009): The genetic and molecular regulation of sleep: from fruit flies to humans. Nat Rev Neurosci 10:549-560.
Cirelli C, Huber R, Gopalakrishnan A, Southard TL, Tononi G (2005): Locus ceruleus control of slow-wave homeostasis. J Neurosci 25: 4503-4511.

Dowling TE, Martasian DP, Jeffery WR (2002): Evidence for multiple genetic forms with similar eyeless phenotypes in the blind cavefish, Astyanax mexicanus. Mol Biol Evol 19: 446-455.

Duboue ER, Keene AC, Borowsky RL (2011): Evolutionary convergence on sleep loss in cavefish populations. Curr Biol 21:671-676.

Ercolini A, Berti R, Chelazzi L, Messana G (1987): Oxygen consumption in hypogean and epigean cyprinids (pisces). Ital J Zool 4: 23-30. 
- Filippi A, Mahler J, Schweitzer J, Driever W (2010): Expression of the paralogoustyrosine hydroxylase encoding genes th 1 and th 2 reveals the full complement of dopaminergic and noradrenergic neurons in zebrafish larval and juvenile brain. J Comp Neurol 518: 423-438.

-Hunsley MS, Curtis WR, Palmiter RD (2006) Behavioral and sleep/wake characteristics of mice lacking norepinephrine and hypocretin. Genes Brain Behav 5:451-457.

Jang YJ, Yu SH, Lee ES, Jeon CJ (2011): Two types of tyrosine hydroxylase-immunoreactive neurons in the zebrafish retina. Neurosci Res 71:124-133.

Lebestky T, Chang JS, Dankert H, Zelnik L, Kim YC, Han KA, Wolf FW, Perona P, Anderson DJ (2009): Two different forms of arousal in Drosophila are oppositely regulated by the dopamine D1 receptor ortholog DopR via distinct neural circuits. Neuron 64:522-536.

- Lesku JA, Roth TC 2nd, Amlaner CJ, Lima SL (2006): A phylogenetic analysis of sleep architecture in mammals: the integration of anatomy, physiology, and ecology. Am Nat 168:441-453.

- Lin L, Faraco J, Li R, Kadotani H, Rogers W, Lin X, Qiu X, de Jong PJ, Nishino S, Mignot E (1999): The sleep disorder canine narcolepsy is caused by a mutation in the hypocretin (orexin) receptor 2 gene. Cell 98:365-376.

-Lopez-Olmeda JF, Tartaglione EV, de la Iglesia HO, Sanchez-Vazquez FJ (2010): Feeding entrainment of food-anticipatory activity and perl expression in the brain and liver of zebrafish under different lighting and feeding conditions. Chronobiol Int 27:1380-1400.

Mendelson WB, Gillin JC, Dawson SD, Lewy AJ, Wyatt RJ (1980): Effects of melatonin and propranolol on sleep of the rat. Brain Res 201: 240-244.

Mitchell RW, Russell WH, Elliott WR (1977): Mexican Eyeless Characin Fishes, Genus Astyanax: Environment, Distribution, and Evolution. Lubbock, Texas Tech Press.

-Moruzzi G, Magoun HW (1949): Brain stem reticular formation and activation of the EEG. Electroencephalogr Clin Neurophysiol 1: 455-473.

-Ornelas-Garcia CP, Dominguez-Dominguez O, Doadrio I (2008): Evolutionary history of the fish genus Astyanax Baird \& Girard (1854) (Actinopterygii, Characidae) in Mesoamerica reveals multiple morphological homoplasies. BMC Evol Biol 8:340.
Parmentier R, Ohtsu H, Djebbara-Hannas Z, Valatx JL, Watanabe T, Lin JS (2002): Anatomical, physiological, and pharmacological characteristics of histidine decarboxylase knock-out mice: evidence for the role of brain histamine in behavioral and sleepwake control. J Neurosci 22:7695-7711.

Plath M, Seggel U, Burmeister H, Heubel KU, Schlupp I (2006): Choosy males from the underground: male mating preferences in surface- and cave-dwelling atlantic mollies (Poecilia mexicana). Naturwissenschaften 93:103-109.

Pollock MS, Mistlberger RE (2003): Rapid eye movement sleep induction by microinjection of the GABA-A antagonist bicuculline into the dorsal subcoeruleus area of the rat. Brain Res 962:68-77.

Poulson TL, White WB (1969): The cave environment. Science 165:971-981.

- Prober DA, Rihel J, Onah AA, Sung RJ, Schier AF (2006): Hypocretin/orexinover expression induces an insomnia-like phenotype in zebrafish. J Neurosci 26:13400-13410.

- Protas M, Tabansky I, Conrad M, Gross JB, Vidal O, Tabin CJ, Borowsky R (2008): Multi-trait evolution in a cave fish, Astyanax mexicanus. Evol Dev 10:196-209.

Rihel J, Prober DA, Arvanites A, Lam K, Zimmerman S, Jang S, Haggarty SJ, Kokel D, Rubin LL, Peterson RT, Schier AF (2010a): Zebrafish behavioral profiling links drugs to biological targets and rest/wake regulation. Science 327:348-351.

Rihel J, Prober DA, Schier AF (2010b): Monitoring sleep and arousal in zebrafish. Methods Cell Biol 100:281-294.

Ruuskanen JO, Xhaard H, Marjamaki A, Salaneck E, Salminen T, Yan YL, Postlethwait JH, Johnson MS, Larhammar D, Scheinin M (2004): Identification of duplicated fourth alpha2-adrenergic receptor subtype by cloning and mapping of five receptor genes in zebrafish. Mol Biol Evol 21:14-28.

- Salin K, Voituron Y, Mourin J, Hervant F (2010): Cave colonization without fasting capacities: an example with the fish Astyanax fasciatus mexicanus. Comp Biochem Physiol A Mol Integr Physiol 156:451-457.
Schemmel C (1980): Studies on the genetics of feeding behaviour in the cave fish Astyanax mexicanus f. Anoptichthys: an example of apparent monofactorial inheritance by polygenes. Z Tierpsychol 53:9-22.

- Simon C, Kezunovic N, Williams DK, Urbano FJ, Garcia-Rill E (2011): Cholinergic and glutamatergic agonists induce gamma frequency activity in dorsal subcoeruleus nucleus neurons. Am J Physiol Cell Physiol 301:C327C335.

Stone WS, Walker DL, Gold PE (1992): Sleep deficits in rats after NMDA receptor blockade. Physiol Behav 52:609-612.

Strecker U, Bernatchez L, Wilkens H (2003): Genetic divergence between cave and surface populations of Astyanax in Mexico (Characidae, Teleostei). Mol Ecol 12:699-710.

-Strecker U, Faundez VH, Wilkens H (2004): Phylogeography of surface and cave Astyanax (Teleostei) from Central and North America based on cytochrome b sequence data. Mol Phylogenet Evol 33:469-481.

Team RDC (2011): R: A Language and Environment for Statistical Computing. Vienna, R Foundation for Statistical Computing.

- Tobler I, Kopp C, Deboer T, Rudolph U (2001) Diazepam-induced changes in sleep: role of the alpha $1 \mathrm{GABA}(\mathrm{A})$ receptor subtype. Proc Natl Acad Sci USA 98:6464-6469.

-Whitehurst VE, Vick JA, Alleva FR, Zhang J, Joseph X, Balazs T (1999): Reversal of propranolol blockade of adrenergic receptors and related toxicity with drugs that increase cyclic amp. Proc Soc Exp Biol Med 221:382-385.

-Wisor JP, Wurts SW, Hall FS, Lesch KP, Murphy DL, Uhl GR, Edgar DM (2003): Altered rapid eye movement sleep timing in serotonin transporter knockout mice. Neuroreport 14: 233-238.

-Yamamoto K, Ruuskanen JO, Wullimann MF, Vernier P (2011): Differential expression of dopaminergic cell markers in the adult zebrafish forebrain. J Comp Neurol 519:576598.

Yamamoto K, Vernier P (2011): The evolution of dopamine systems in chordates. Front Neuroanat $5: 21$.

-Yokogawa T, Marin W, Faraco J, Pezeron G, Appelbaum L, Zhang J, Rosa F, Mourrain P, Mignot E (2007): Characterization of sleep in zebrafish and insomnia in hypocretin receptor mutants. PLoS Biol 5:e277.

-Yoshizawa M, Goricki S, Soares D, Jeffery WR (2010): Evolution of a behavioral shift mediated by superficial neuromasts helps cavefish find food in darkness. Curr Biol 20:16311636. 